\title{
El desaparecido cine La Iberia, de Sestao. Santos Zunzunegui
}

\author{
Ana Julia Gómez Gómez *
}

\section{EL ARQUITECTO, SU ENTORNO Y SU TIEMPO}

La figura del arquitecto vizcaíno Santos Zunzunegui Echebarría es bastante desconocida en la actualidad '. Sus coetáneos: Severino Achúcarro, Manuel María de Smith, Leonardo Rucabado, Ricardo Bastida y Amánn, entre otros, han acaparado el interés de los investigadores, obviándose el trabajo de Santos Zunzunegui, a pesar de conservarse en gran parte su obra y acreditar la valía de su autor.

Toda su obra se fecha en la primera mitad del siglo xx, y se circunscribe principalmente a Vizcaya, centrándose su quehacer arquitectónico en la Margen Izquierda del Nervión: Portugalete, Sestao y Baracaldo. Paralelamente a su interés por la arquitectura tuvo otro, el político ${ }^{2}$. Este segundo, es precisamente el que hace complicado y difícil el estudio del primero, ya que durante la Guerra Civil española, se quemó o perdió toda la documentación que poseía el arquitecto. Únicamente contamos con los proyectos conservados en los Ayuntamientos de Portugalete, Baracaldo y posiblemente de Sestao $^{3}$.

* Lda. H. ${ }^{a}$ del Arte.

Sobre Zunzunegui, véase la comunicación de Gorka Pérez de la Peña, presentada al Symposium «El papel y la Función del Arte en el siglo $x \times »$, organizado por la Universidad del País Vasco en noviembre de 1991 en Bilbao.

De tendencias y sentimientos monárquicos, su interés por la política le llevó en dos ocasiones a la alcaldía de Portugalete, fue durante el bienio de 1916-1917 y en el trienio 19231925.

En 1925, el 18 de agosto, causó baja por enfermedad, auseniándose del cargo de alcalde. Siete meses después renuncia a sus cargos de concejal y de alcalde en el ayuntamiento, por incompatibilidad con el de Diputado provincial, para el que ha sido nombrado, siendo investido por disposición gubernativa. Esto ocurría el 6 de marzo de 1926 . Este mismo año se hizo cargo de la presidencia de la comisión de viviendas de la Diputación.

3 Actualmente el archivo municipal de Sestao se encuentra cerrado al público. Falta por 
Santos Zunzunegui ejerció la profesión en un momento de gran crecimiento industrial de la Margen Izquierda. A principios de siglo se crearon los Altos Hornos de Vizcaya, la empresa siderometalúrgica más importante del país. Junto a ella surgen los astilleros del Nervión y, unos años después, en 1915, la Naval, ubicadas todas ellas en el núcleo municipal de Sestao.

Estas grandes empresas, junto con otras fábricas y la gran masa de inmigrantes de otras provincias que se vieron atraídos por los numerosos puestos de trabajo que se generaban, harán de Sestao y su vecino Baracaldo el núcleo industrial y de densidad demográfica ${ }^{4}$ más importante del País Vasco, importancia que aún hoy conserva.

Estas circunstancias provocan un desarrollo urbanístico importante del pequeño concejo de Sestao, que posee un total 3,70 kilómetros cuadrados.

En este núcleo urbano es donde Zunzunegui actuará como arquitecto municipal, proyectando un considerable número de edificios y supervisando todos los que se construyen, dentro de un marco demográfico - geográfico un tanto complejo, ya que se produjo un espacio muy congestionado por las áreas industriales, que suponen $3 / 4$ partes de la superficie municipal.

La expansión urbanística de Sestao se articula en torno a las fábricas, que van surgiendo a su alrededor como si de un cinturón se tratase. Este hecho se convierte en un foco de atracción, al cumplir la característica de cercanía entre la vivienda del trabajador y la factoría de producción.

Vivió en Portugalete, municipio colindante a Sestao, villa de recreo por aquel entonces de la aristocracia española y de la creciente burguesía vasca, y donde actualmente quedan notables edificios por él proyectados, pudiéndose estudiar su modo de hacer y los estilos utilizados. Primando el eclecticismo, con abundantes notas clásicas, y el gusto por la edificiación inglesa.

Hay que tener en cuenta que en las dos últimas décadas del pasado siglo, junto con las tres primeras del siglo xx, arquitectónicamente Biibao

organizar toda la documentación anterior al año 1940. Posiblemente este archivo guarde información que ayude a conocer mejor el trabajo realizado por Santos Zunzunegui.

${ }_{4}^{4}$ En 1887 el crecimiento humano se sitúa en más de un $20 \%$ respecto a 1877 , llegando a 3.499 habitantes. El desarrollo urbano está condicionado por estas cifras de población, que se revolucionan al entrar en el siglo xx. El vecindario de Sestao llega a 11.800 habitantes en 1910 . Otro tanto ocurre en los años veinte, con importantes plantas de transformados metálicos y maquinaria. 
y su provincia seguirán las pautas que se dan en el resto del país e incluso en el extranjero. Así, en Vizcaya, nos encontramos con un fuerte eclecticismo, no teniendo demasiado arraigo los movimientos historicistas. Son contados los edificios neorrománicos o neogóticos. Las tendencias modernistas tampoco calan en el sentido estético del vizcaíno, se reducen a una docena de edificios los que poseen este lenguaje. Incluso Zunzunegui que conocía el modernismo catalán directamente, ya que estudió la carrera en Barcelona, lo utiliza de modo muy esporádico y únicamente a modo de detalle, como ocurre en la puerta del antiguo cuartel de la Guardia Civil de Sestao.

Bien al contrario, prolifera la imitación del elegante edificio inglés. Los continuos viajes a ese país de los empresarios de la siderometalúrgia vasca, y el asentamiento de colonias británicas en esta zona, mostraron una arquitectura sobria y elegante, que inmediatamente ahondó en el gusto de la nueva burguesía vasca que encontró en esta arquitectura un modo de mostrar su creciente poder económico.

Muestra de ello son las casas del Ensanche Bilbaíno, las de Neguri, y las del muelle de Portugalete que Zunzunegui realizó para las más prestigiosas familias de la época.

Aunque en Sestao también tuvo encargos para casas nobles, son un número más reducido y no es lo más representativo de lo realizado por el arquitecto en este pueblo. De cualquier modo, trabajó en este municipio más libremente, ya que la mayoría fueron obras municipales, donde podía disponer de su criterio y autoridad en materia arquitectónica, siendo precisamente en Sestao donde realizó su único cine, derruido en la primavera de 1991, motivo de este estudio.

\section{ZUNZUNEGUI, ARQUITECTO MUNICIPAL DE SESTAO}

Durante treinta y dos años fue arquitecto municipal de Sestao, desde $1913^{5}$ hasta su fallecimiento en septiembre de 1945.

Conocedor de la infraestructura social y política de este pueblo, realizó importantes edificios:

Es importante para el arquitecto, el año de 1913, ya que parece consolidarse, después de doce años de terminar la carrera, en tres aspectos profesionales importantes: como profesor de la Escuela de Artes y Oficios de Baracaldo, como arquitecto municipal de Sestao y abriendo su nuevo estudio en lo más céntrico de Bilbao. para recoger los encargos de la burguesía bilbaina. 
- La Escuela Municipal Carlos VII (1910-1912), de tendencia clásica, remodelada en abril de 1989 y, que actualmente da cabida al conservatorio de música. Conserva la fachada principal, con muy pocas variaciones respecto a la original.

- La Casa Cuartel, para la Guardia Civil (1912-1914), con cierta nota modernista en su puerta principal ${ }^{6}$.

- El edificio para la primera sucursal de la Caja de Ahorros Municipal de Bilbao (1926), aunque mal conservada mantiene un profuso lenguaje neoclásico.

- El Cine La Iberia, en la calle del mismo nombre (1929), que a continuación se estudia.

- Numerosas casas de vecindad ya fueran dobles, triples o individuales, como son los casos entre otros de la casa para Tiburcio Ellacuría, en la calle Veinticinco de Diciembre, la casa para Doroteo Corraleche en la calle la Llanas o el número 10 de la calle San Diego, asi como las agrupaciones de casas para obreros: La Humanitaria, La Aurora, La Protectora, y la Unión. Son las denominadas casas baratas, realizadas por los grandes empresarios de las fábricas del pueblo, para sus trabajadores. Son importantes en este caso, tanto por la dignidad de construcción, como por el planteamiento de vivienda en la línea del inglés Lever discípulo de Ruskin y Le Play, quién creó Port Sunlight, a finales del siglo pasado, donde un jardín adornaba el frente de la casa y en la parte trasera había un huerto.

Zunzunegui parece conocer las teorías de los ingleses, quienes observaron que a los obreros, normalmente inmigrantes del campo, les venía bien la doble práctica del trabajo industrial y de la labor agrícola. Ésta les servía para escapar psicológicamente del aspecto fabril en el que se movian y, por otro lado, para ahorrar en productos de consumo diario de huerta y a través de la pequeña crianza, normalmente avícola.

Cualquiera de las barriadas para obreros construidas por él son casas bien proyectadas, con su zona ajardinada o pequeña huerta. Los interiores son acogedores, con una distribución correcta y con los espacios necesarios para una vivienda digna. Observaba el entorno y el ambiente que rodeaba a la edificación, procurando pensar en los inquilinos y buscando el decoro en sus trabajos.

6 Actualmente este edificio se mantiene, y se puede ver su gran puerta modernista, único detalle de este estilo en el edificio. De todos modos su estado de conservación es lamentable y está considerado fuera de ordenamiento urbano. Por lo cual puede ser demolido en breve. 
EL CINE DE LA IBERIA (fig. 12)

Como ya se ha dicho, Sestao era un núcleo urbano superpoblado por la fuerte industrialización. Aglomeraba a una población que, además del baile en la plaza del casco y del fútbol, necesitaba alguna alternativa de distracción. Esto era lo que podía ofrecer el reciente cinematógrafo.

Tal necesidad se vio cumplida con la iniciativa de proyectar películas en un garaje, que con el tiempo se le conoció como Cine El Garaje, a pesar de que nunca dejó de ser una lonja, en la que en un principio había que llevar la silla o sentarse en el suelo.

Este cine fue el primero que tuvo el pueblo, y las autoridades del momento se plantearon crear un local adecuado a tal fin. Para ello, pidieron un proyecto de cine al arquitecto que en aquel momento más conocía la materia: Teodoro Anasagasti ?

Esta gestión se realizó el año 1922. Para entonces, Anasagasti habia realizado el Real Cinema de Madrid, el Fontalba, que era también teatro, y terminaba el Monumental Cinema. Proyectó un cine para Sestao (figs. $1,2,3,4$ y 5) como se le habia pedido, en un lugar determinado, que sin embargo no es concordante en plano con la ubicación posterior del edificio que se llevó a término ${ }^{8}$.

Se desconoce el motivo por el que este arquitecto no construyó el cine. El hecho es que siete años después, en 1929, la adinerada familia Solano compra un terreno en la calle más transitada de Sestao, La Cuesta de La Iberia, con la finalidad de edificar un cinematógrafo (fig. 6). Esta solicitud fue aprobada por el ayuntamiento, y se realizó el cine, en base a) proyecto que presentaba Zunzunegui.

Los planos entregados junto a la solicitud de Solano prácticamente no fueron variados, tan sólo se hizo en un detalle mínimo, los servicios de la zona izquierda del edificio. Sobre el piso de butacas, Zunzunegui concibió la planta de entrepiso, y la de anfiteatro (fig. 7, 8 y 9), llevándose a cabo todo lo ideado.

Sobre este arquitecto y su aportación a las salas Cinematográficas ver GARCia MoraLES. Maria Victoria, "Teodoro de Anasagasti Algán», en Arquitectura Madrileña de la primera mitad del siglo xx. Marzo 1987. Madrid, págs. 63-91.

- Según Alberto González delineante del ayuntamiento de Sestao, ve claramente que es imposible situar el proyecto de este arquitecto en el terreno en el que posteriormente se levanta el cine. El, después de consultar los planos del pueblo, coloca la idea de Anasagasti al final de la calle de los Baños, cercana a la calle Chávarri. 


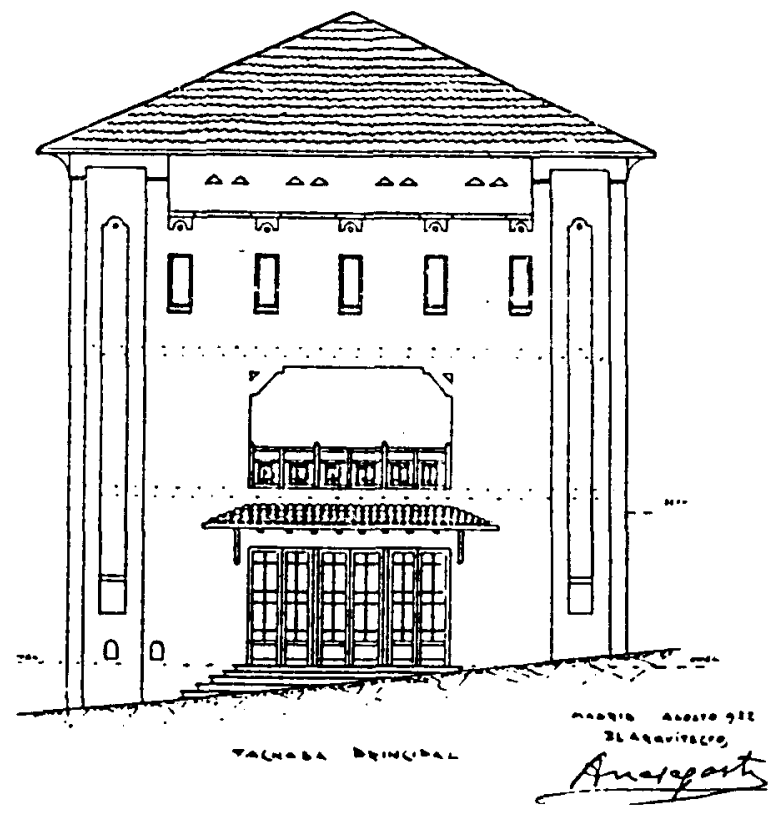

Fig. 1. Fachada del cine proyectada por Anasagasti.

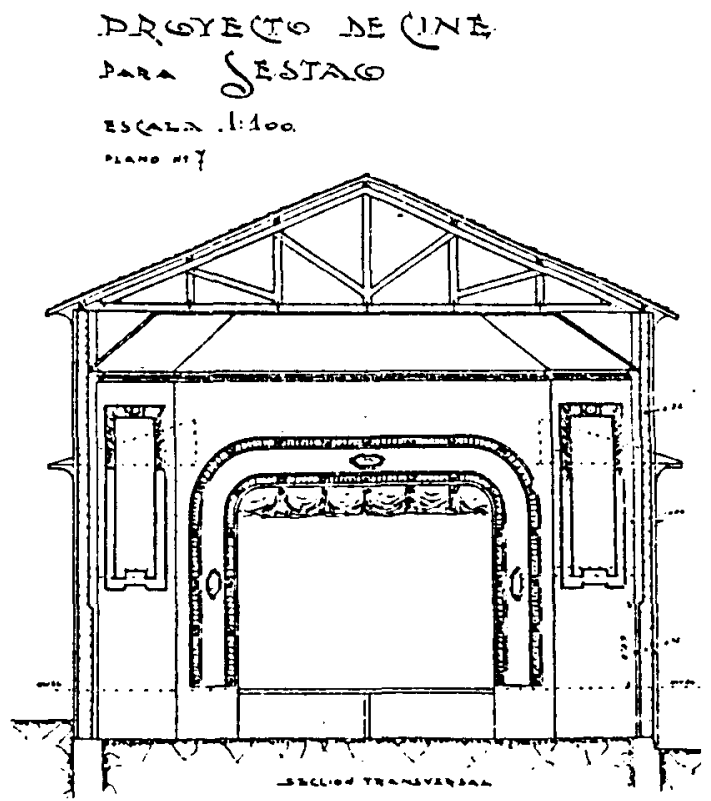

Fig. 2. Escenario del cine, proyectado por Anasagasti. 


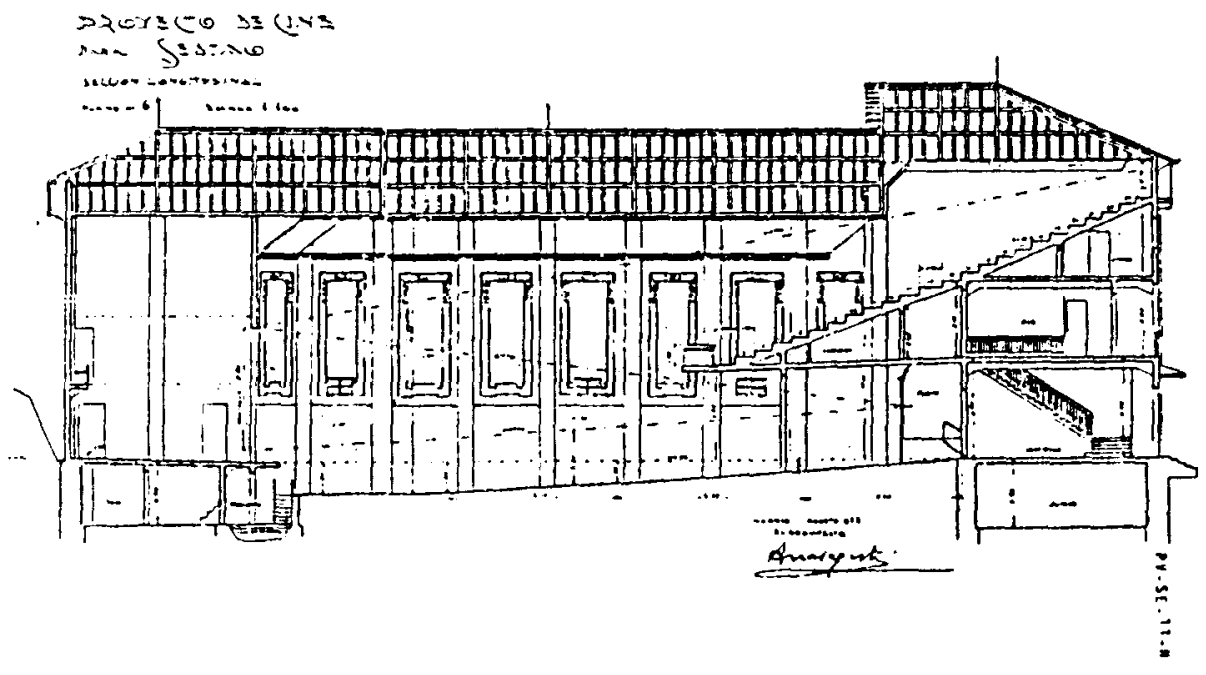

Fig. 3. Sección longitudinal del cine, proyectada por Anasagasti.

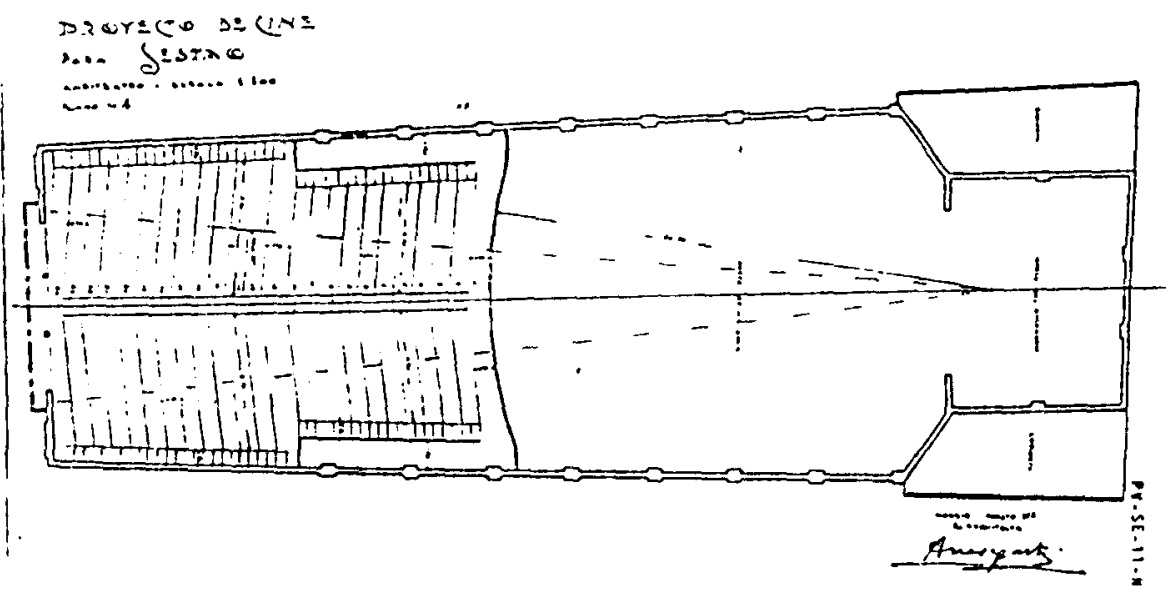

Fig. 4. Anfiteatro del cine, proyectado por Anasagasti. 


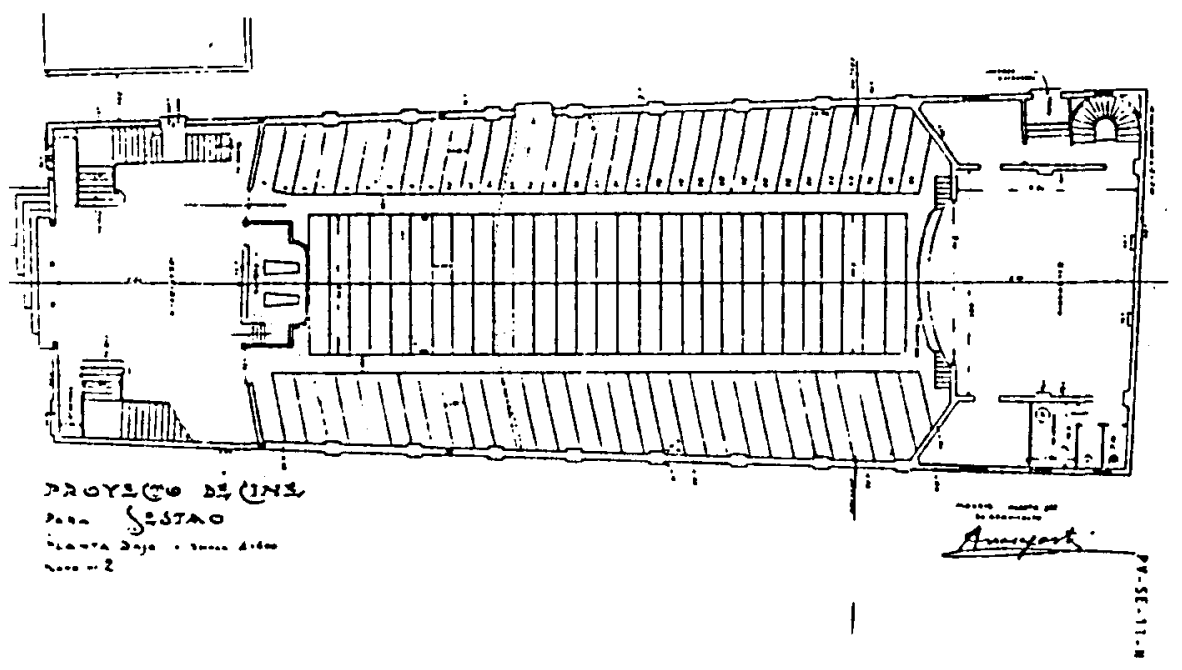

Fig. 5. Planta baja del cine, proyectada por Anasagasti.

Los cines, al ser obras nuevas, sin lenguaje definido en aquellos años, permitían libertad de proyecto, dentro de unas pautas lógicas y racionales, $y$, aunque Zunzunegui había edificado el teatro de Portugalete, el cinematógrafo tenía premisas nuevas y exclusivas, que planteaban un tipo de soluciones inéditas y originales.

Ya en 1919, tuvo que plantearse Zunzunegui un proyecto con el título de Sala de Espectáculos, cuyo fin era el de Sala Cinematográfica, para el Ayuntamiento de Portugalete, con fachada principal a la calle General Castaños. No se llevó a cabo y diez años después se construyó un cine en el mismo lugar, pero bajo proyecto de Angel Berriatúa Pagazaurtundua.

\section{Emplazamiento}

La ubicación del cinematógrafo pasó a ser decisión a considerar en todos los municipios, ya que producía una concentración de personal que causaba cambios en la fisonomía del entorno.

A este respecto hay que recordar, una vez más, que Sestao está levantado en una colina, donde el núcleo urbano está en la cima y las industrias en la parte baja, formando un cinturón. Unas de las calles más importantes de los años veinte fue La Iberia ${ }^{9}$.

9 Actualmente también es una calle principal, pero en las últimas décadas se han embellecido muchas otras, que han dejado a La Iberia en un plano inferior. 
necreto. Sestio a 17 de Ju110 de 1929.

Pase a infarme de la sección of obras.

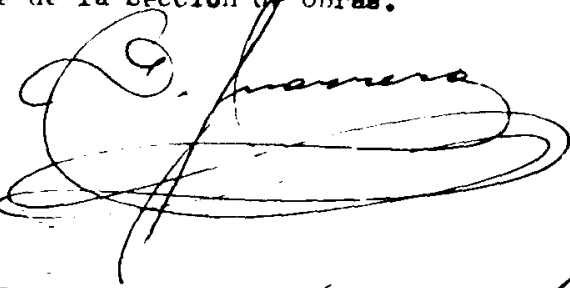

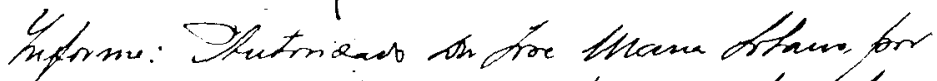

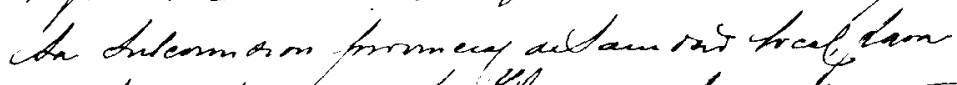

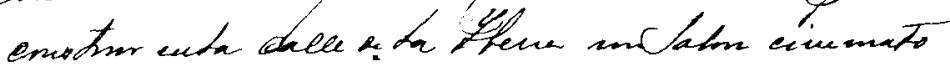

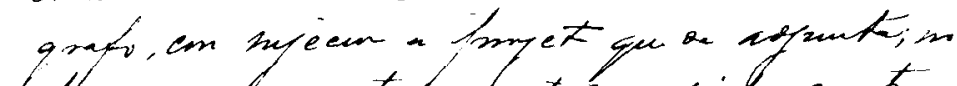

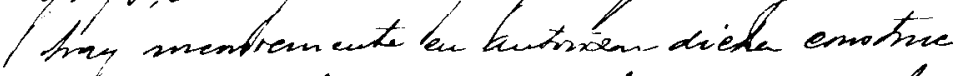

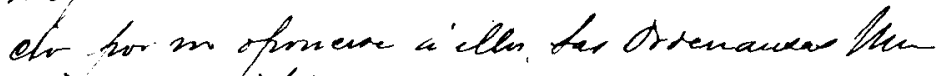
optacs are espexin.

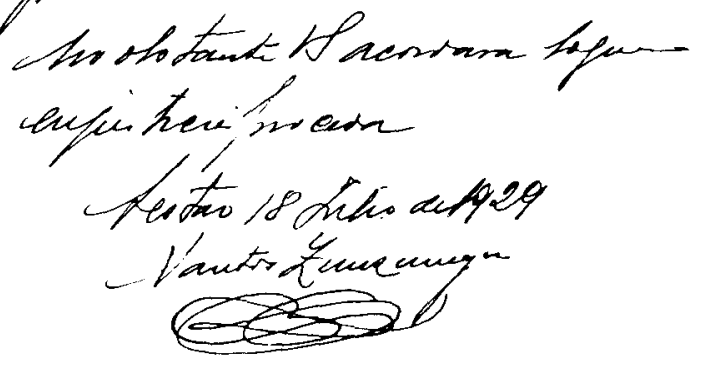

Decreto. Segtao a 18 de Jul10 de 1929.

nese cuente e le Comisión Permenente.

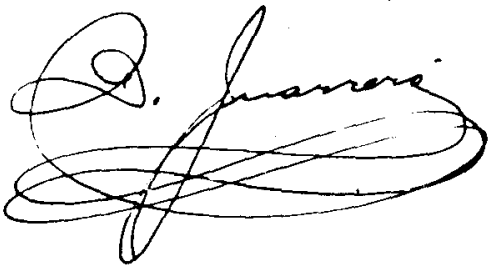

Fig. 6. Informe de Santos Zunzunegui de la sección de obras para la construcción del cine en la calle de la lberia. 


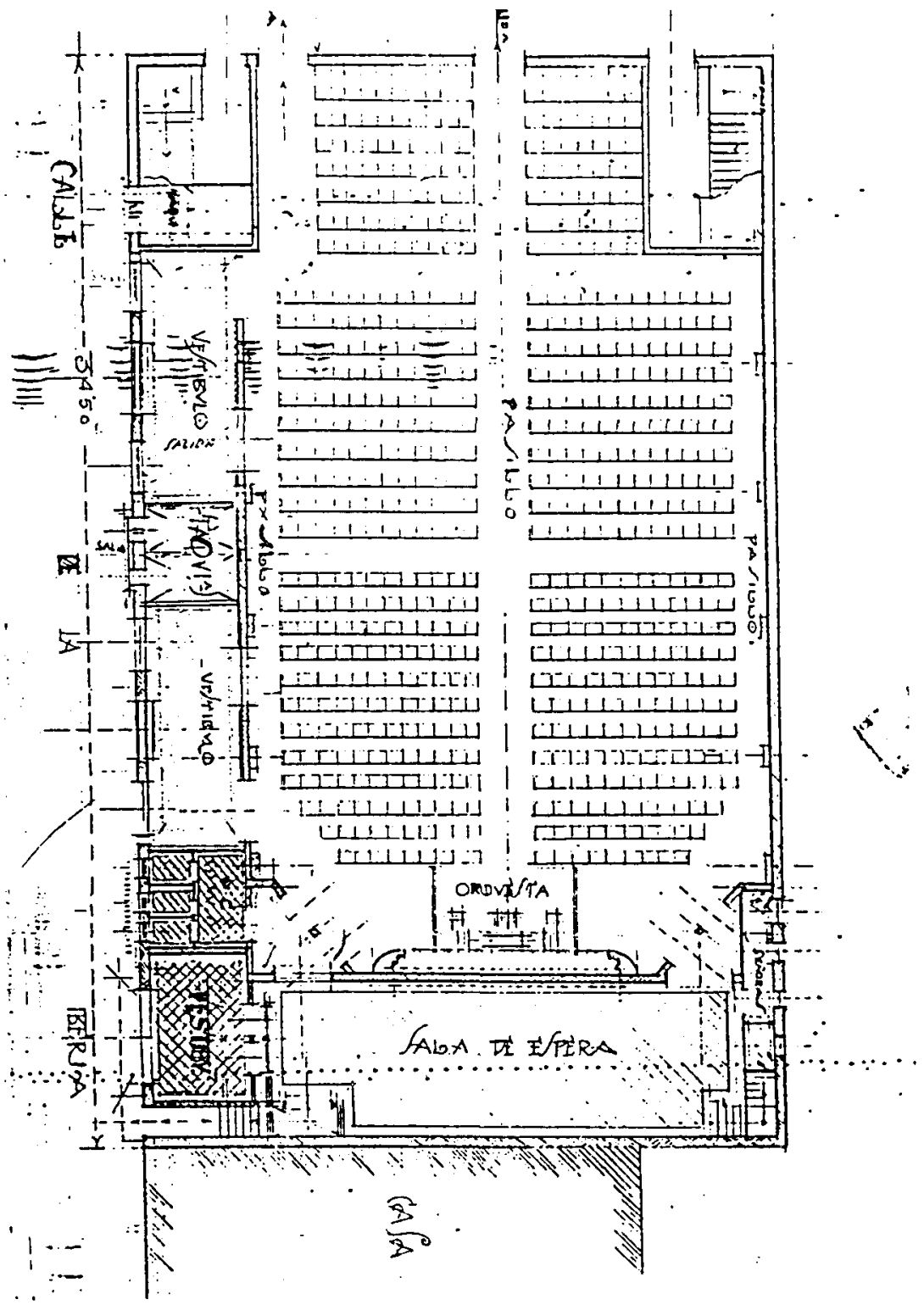

Fig. 7. Planta del patio de butacas proyectado por Zunzunegui. 


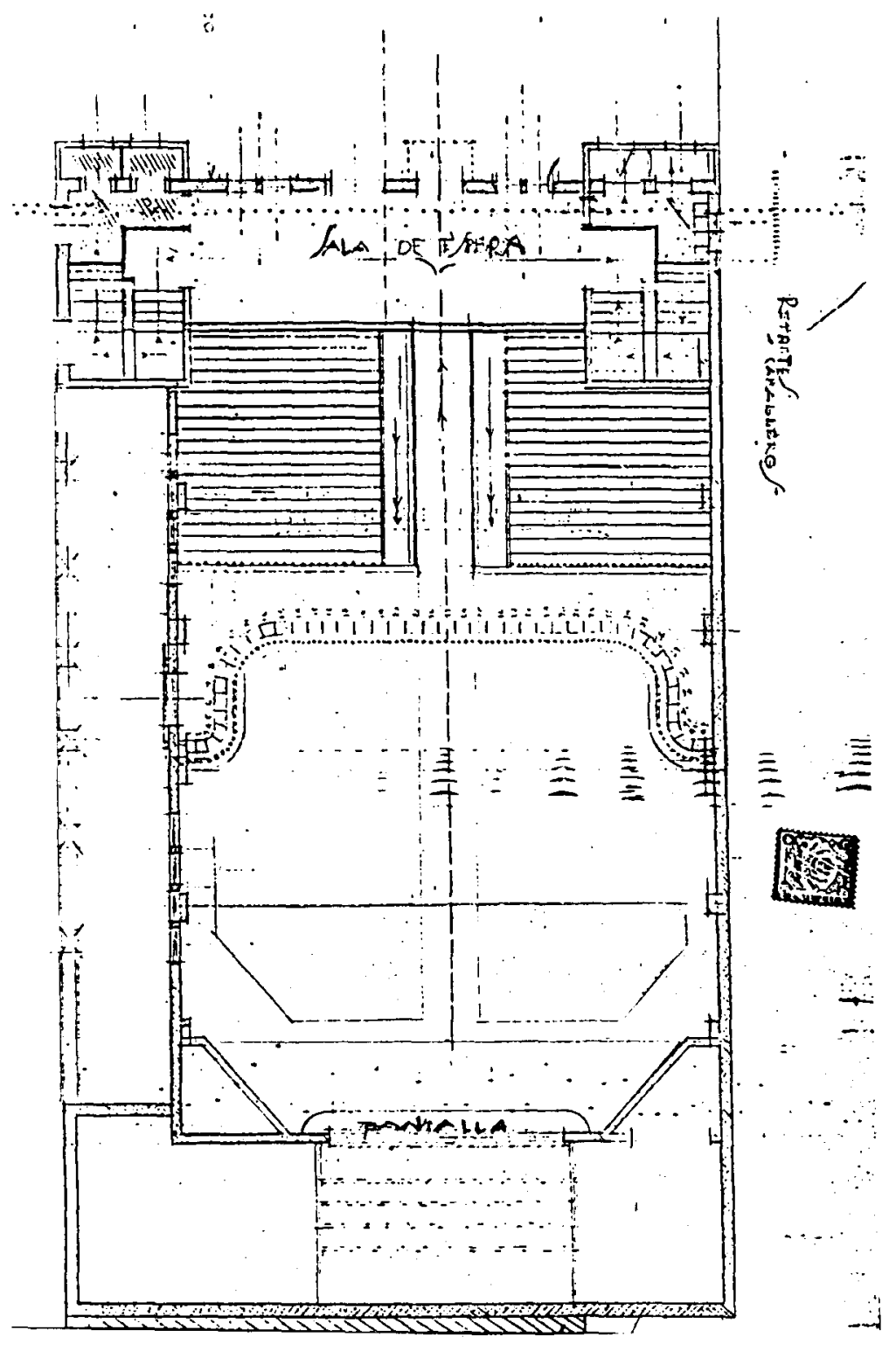

Fig. 8. Planta del entrepiso proyectado por Zunzunegui. 


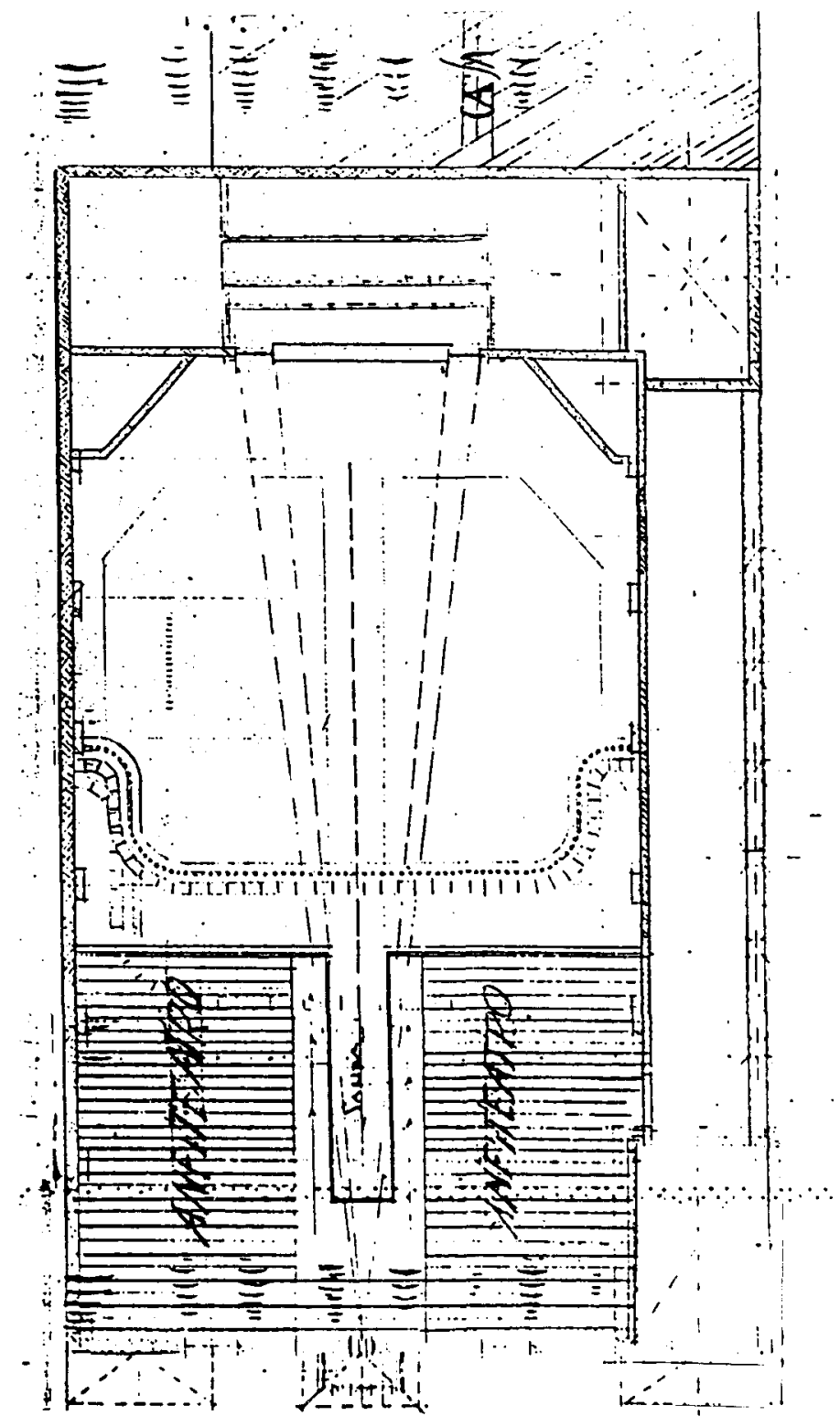

Fig. 9. Planta del anfiteatro proyectado por Zunzunegui. 


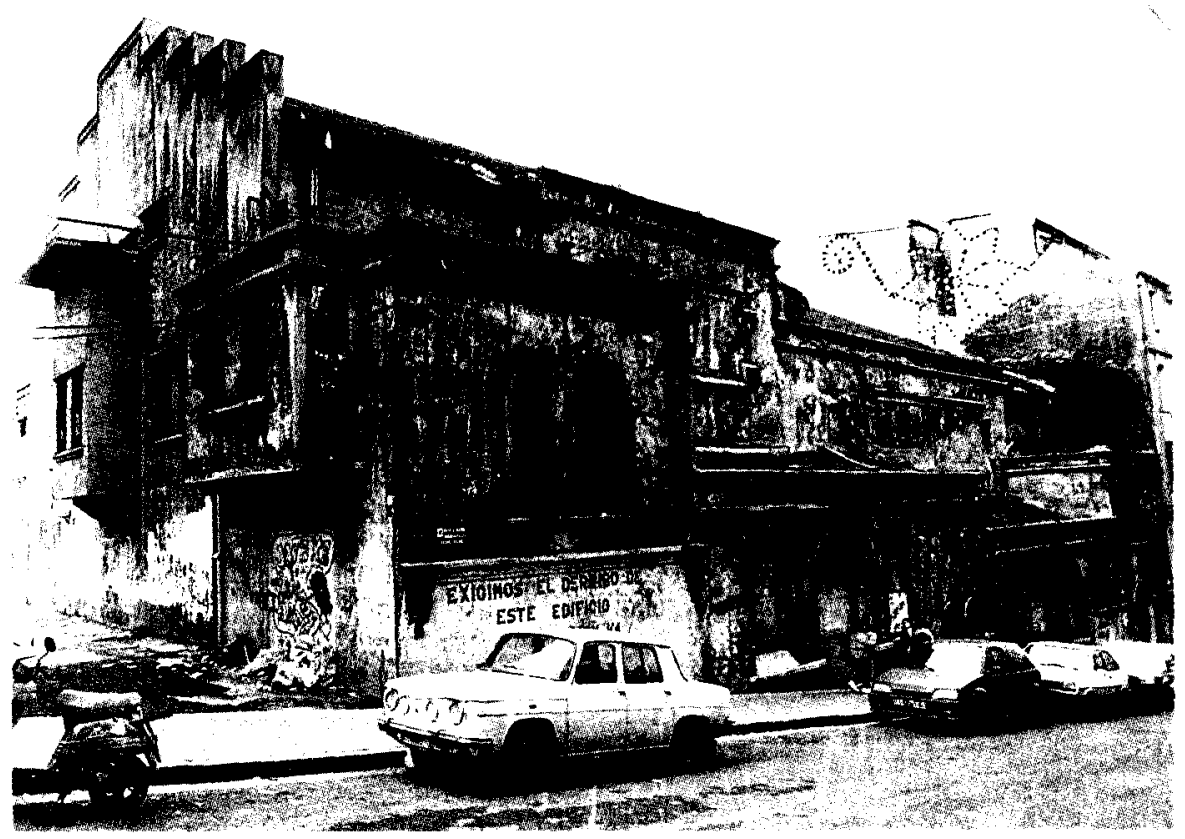

Fig. 10. Fachada principal y lateral del cine La Iberia.

Esta vía une el centro del pueblo con la carretera hacia Bilbao, la estación de ferrocarriles y Altos Hornos. Además, esta calle poseía todo el comercio importante del pueblo en aquel momento. No cabe ninguna duda de que se eligió un excelente lugar para su construcción, a diferencia del hipotético terreno en el que lo iba a realizar Anasagasti, que comenzaba a considerarse alejado del centro urbano y de los grandes edificios municipales.

La cercanía del cine con el centro de expansión del núcleo urbano, la Plaza del Casco, la Campa de la Iglesia, hicieron que se creara una zona de esparcimiento y de comercio muy apreciadas. Concretamente el tramo comprendido entre el cine y la plaza, poseía el mayor número de locales comerciales del municipio. Por otro lado, estaba muy cerca de la cooperativa de Trabajadores de los Altos Hornos, con lo cual la zona de esparcimiento, la comercial y la de trabajo estaban unidas, teniendo una interrelación y comunicación total, formando cada una de ellas parte del devenir diario. 
Exterior (fig. 10)

El cine, en su exterior, era un edificio de planta rectangular, de 20 metros de ancho por 34,5 metros de largo. Erigido sobre fuerte pendiente, con cubierta a dos aguas de caballete paralelo a la fachada de acceso, con dos tramos a diferente alzada. Dicha fachada distribuyó cuatro cuerpos (fig. 10) adosados al muro del edificio, que presentaban modulaciones de líneas rectas coronándolas, que a su vez marcaban la linealidad y remarcaban los volúmenes cúbicos de los distintos cuerpos; los vanos de este sector estaban rematados con arcos.

La primera puerta estaba en el segundo volumen (fig. 10), flanqueada por dos ventanas de arco de medio punto. Esta puerta, al igual que las otras dos, era de arco carpanel, en este tramo estaban las taquillas, también de arcos apainelados. En el siguiente volumen se repetía la misma estructura, sustituyendo las taquillas por ventanas. El último tramo subía en altura, tenía dos vanos inferiores, el primero de arco carpanel daba al tercer vestíbulo, a continuación existía otra puerta, pero en este caso más pequeña y adintelada, que daba a una empinada escalera que comunicaba directamente con el escenario. Sobre la primera puerta se aligeraba el peso con doble ventana, exacta a la del primer volumen.

La fachada lateral (fig. 13), presentaba vanos adintelados y se remataba con frontón escalonado ${ }^{10}$. La otra fachada lateral no existía, al quedar adosada a los edificios alineados a esta calle.

La fachada trasera (fig. 14), daba a zona sin urbanizar, tanto cuando se edificó, como cuando ha sido derribado. Era una pared lisa, en la que únicamente sobresalía los módulos de los servicios, de cubierta de teja-ladrillo.

El edificio era un juego de volúmenes, donde la línea horizontal y quebrada tenía todo el poder. Se diría que Zunzunegui, en este cine, experimentó una tendencia cubista. La decoración era escasa, por no decir inexistente. Todos los ornamentos estaban pensados y eran exiguos, no sólo en el exterior, sino también en el interior. En ellos estaba presente la línea recta, en las líneas en relieve que coronaban cada volumen, y en las dos cartelas (fig. 12).

La línea curva, sólo aparecía en los vanos de la fachada principal, y en dos volutas achatadas (fig. 11), muy escogidas, tanto en forma como

: El Ideal Cinema de Portugalete, también derribado hace un par de años, y que se construyó prácticamente a la vez que el de Sestao, tanía la fachada rematada igual que el de su vecino sestaotarra. 


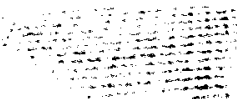

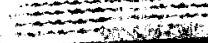

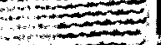

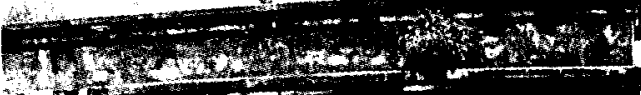
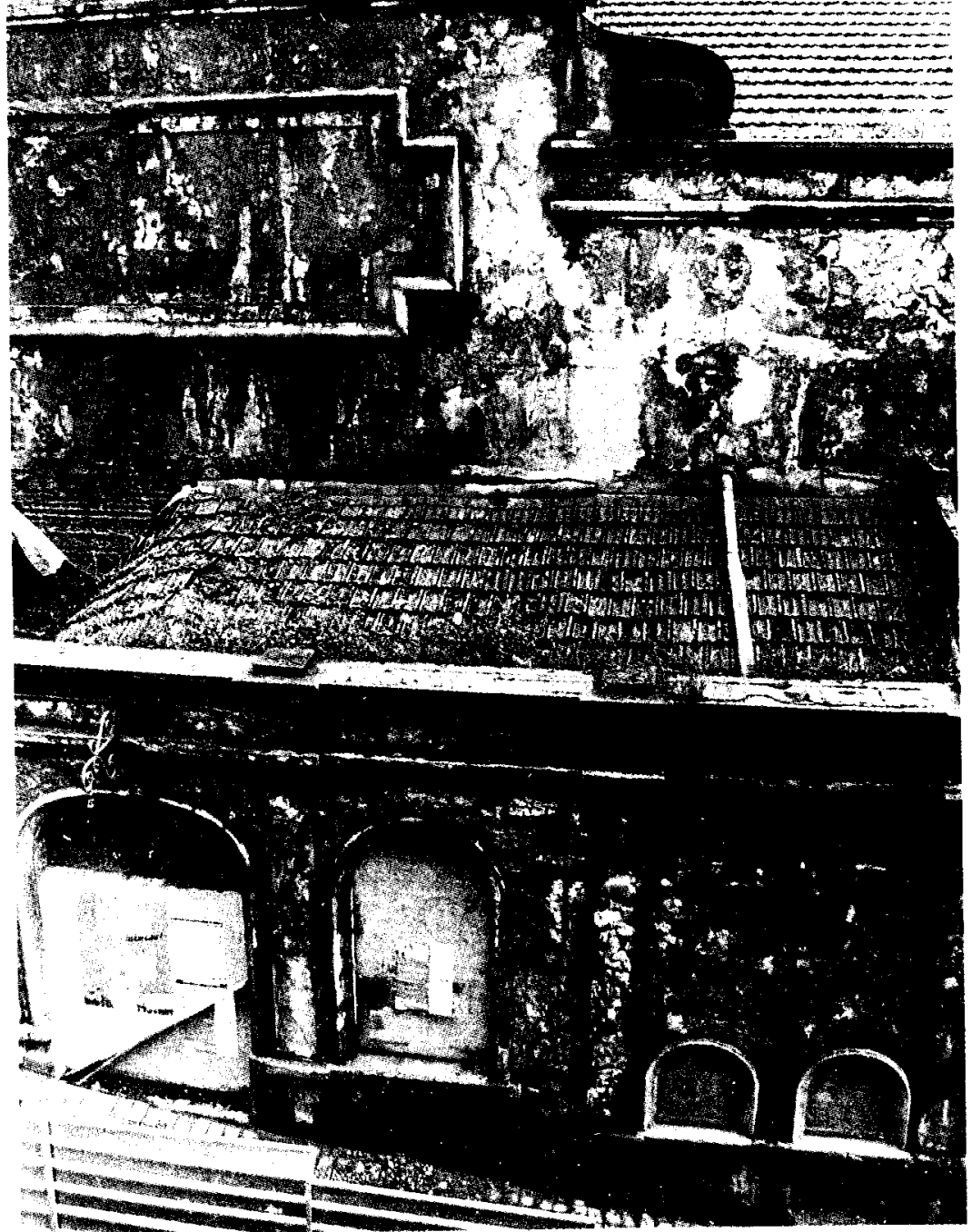

Fig. 11. Cubierta a dos aguas. Detalle de una de las cartelas y de la voluta. Puerta de acceso a las localidades del patio de butacas. Detalle de las taquillas. 


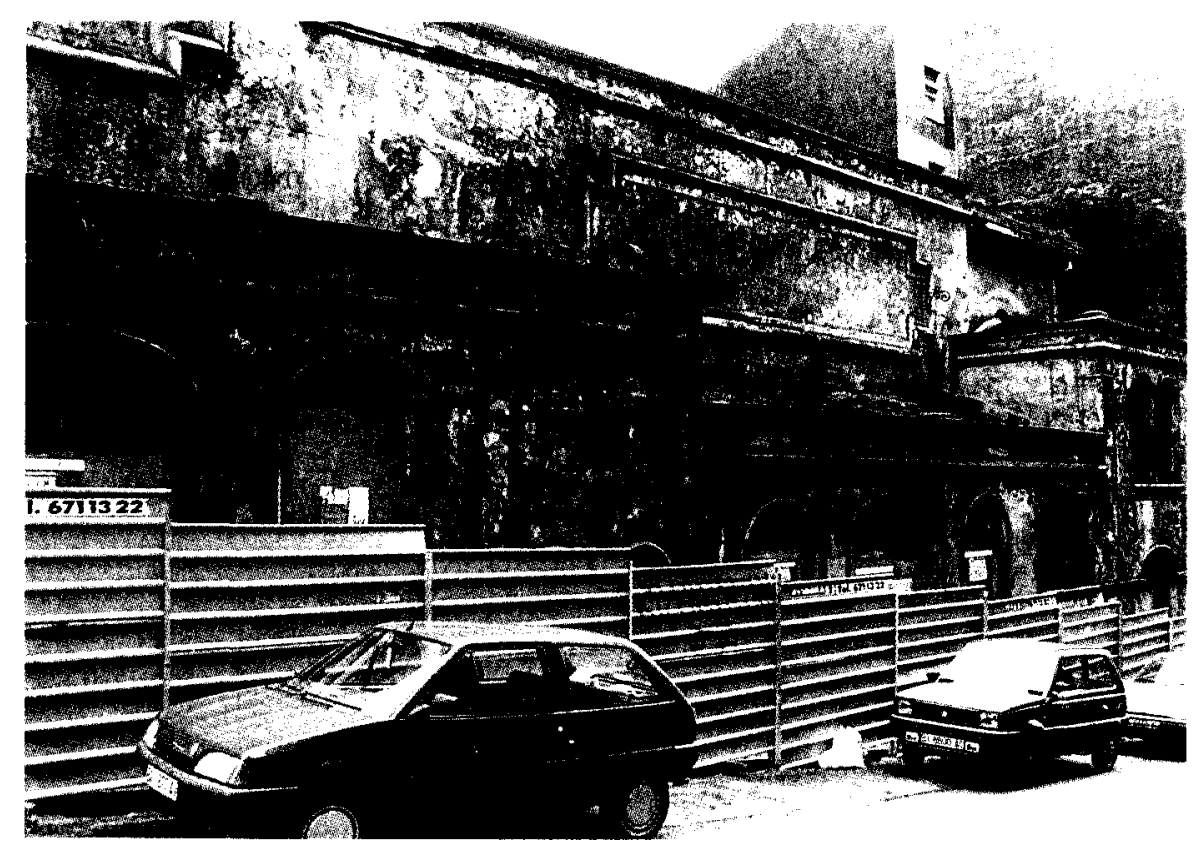

Fig. 12. Lineas rectas coronando los distintos volumenes.

en situación. Estaban colocadas en la misma fachada, pero en planos perpendiculares, volúmenes distintos y alturas diferentes. Con este detalle, Zunzunegui muestra el rechazo que sufre en este edificio la decoración. Sólo dos volutas, una en lo más alto, para que se pueda ver de frente y otra más baja, para animar la vista del paseante en el momento de subir la empinada cuesta de la calle. En este cine el racionalismo de Zunzunegui está firmado.

Su interés por las innovaciones no queda reducido a una tendencia formal, los nuevos materiales tienen un gran interés para el arquitecto. $\mathrm{Ha}$ visto utilizar el hierro y el hormigón a los ingenieros, abundantes en Vizcaya, y algunos íntimos amigos suyos. $Y$ es de suponer que estaba al día en cuanto a los materiales para la construcción de cines por los que abogaba Teodoro Anasagasti, que fue uno de los precursores en la utilización del hormigón armado.

Los materiales utilizados en la construcción del cine La Iberia son: el ladrillo de asta y media en los muros perimetrales; el hormigón armado es usado para la estructura del graderío, para el techo y suelo del anfiteatro, lugares donde se debía soportar una gran resistencia de peso, así 


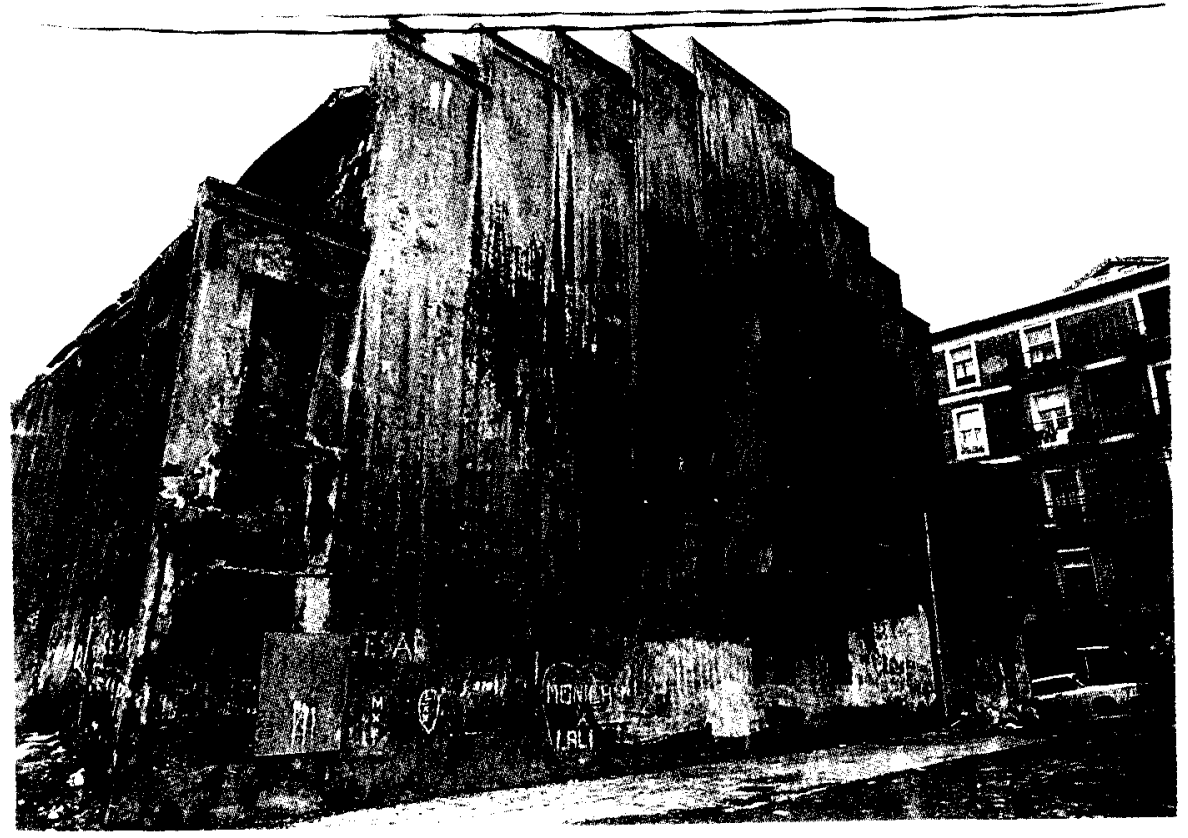

Fig. 13. Fachada lateral.

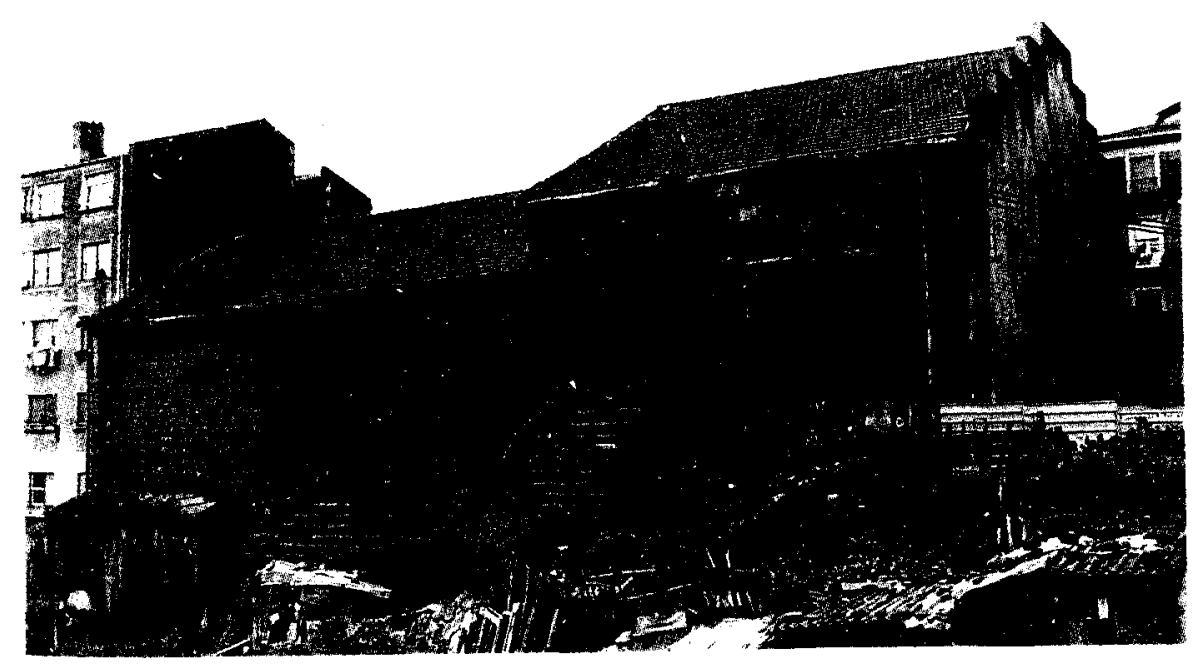

Fig. 14. Fachada trasera del cine La lberia. 
como aguantar todo el voladizo sin columna alguna. La cubierta estaba apoyada en cerchas de hierro. La madera fue empleada en el ensamblaje de inclinación del anfiteatro formando los escalones de las gradas.

En esta misma línea, pero más racionalista aún, tanto por materiales usados como por forma, será el proyecto del mercado de Portugalete (fig. 15) que construye un año después. La función del mismo le exige mayor limpieza de formas y excusa completamente la decoración.

Es una lástima que no se encuentre nada de documentación sobre Santos Zunzunegui, porque con el estudio de este cine y comparándolo con las obras mencionadas anteriormente, se puede afirmar que era un conocedor autorizado en las nuevas tendencias y en la funcionalidad de la arquitectura.

Con esta construcción, el arquitecto parece decirnos que la finalidad del edificio es la utilidad. La decoración la considera superflua. Lo que cuenta ante todo es la adaptación de un edificio a su función. Las formas deben derivarse de una lógica de la construcción y no de una búsqueda de la belleza en sí.

Zunzunegui, con este cine, recuerda las ideas de Jean-Nicolas Louis Durand, $o$ al seguidor de Otto Wagner, A. Loos, que propugnan una desnudez y limpieza en las fachadas y hablan de la belleza de lo práctico. El cine de Zunzunegui es justamente eso, útil.

El juego de volúmenes no es otra cosa que una aligeración de peso y un contrarresto de presiones del muro del edificio, todo ello adaptado a una pendiente del terreno, del cual también intenta sacar provecho en la inclinación del patio de butacas.

Es un edificio totalmente razonado y precisamente en este razonamiento recae la belleza de dicha construcción, poco apreciada por otro lado, por su derribo reciente.

Hay que mencionar que por ahora se desconoce si la que finalmente se realizó fue la idea originaria de la fachada, ya que junto a la solicitud de José María Solano Aguirre, se han encontrado las plantas y un alzado del escenario y pantalla, pero no los planos del exterior ${ }^{11}$. De cualquier modo, el proyecto original, posiblemente se ajustaba a los resultados de acabado, si tenemos en cuenta la concordancia entre el interior ideado y el resultado obtenido.

Por el contrario, si se tiene el alzado de las fachadas proyectadas por Tecdoro Anasa. gasti y no tienen absolutamente nada que ver con el trabajo realizado por Zunzunegui. 


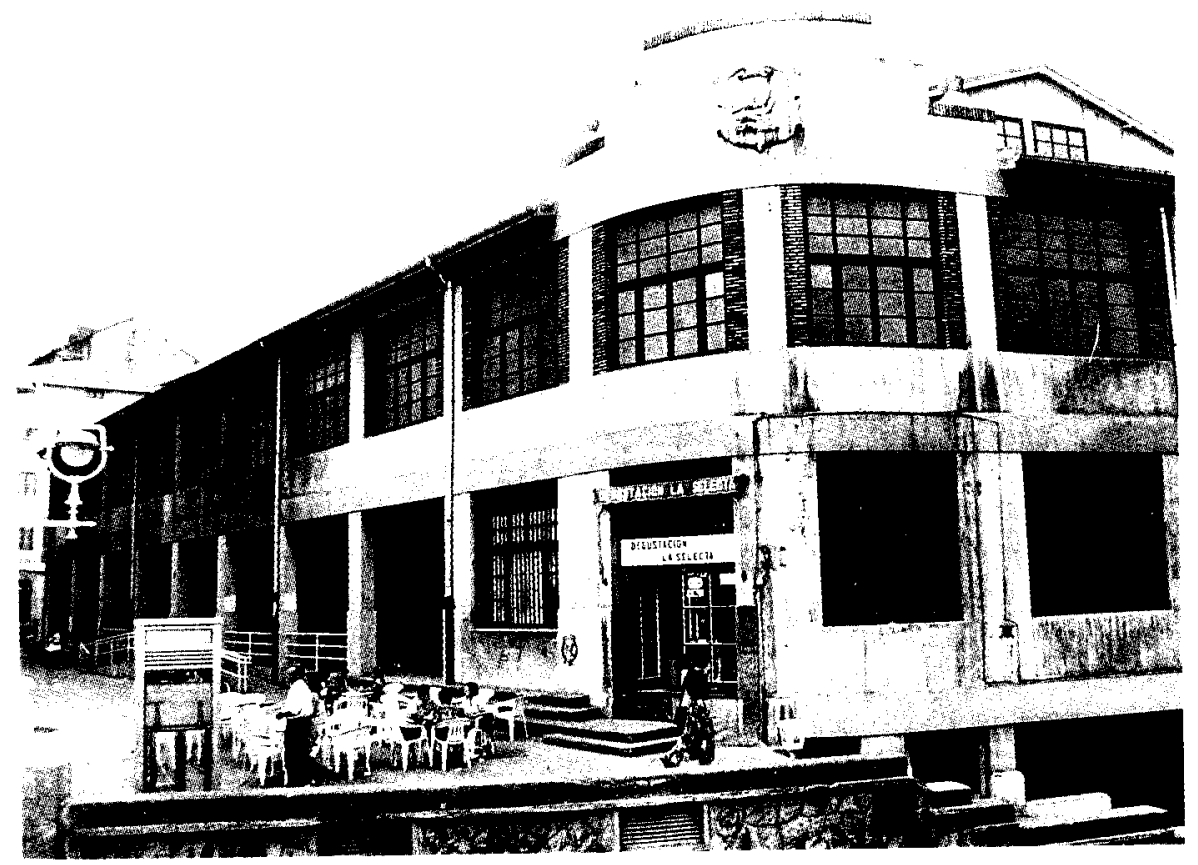

Fig. 15. Mercado Municipal de Portugalete.

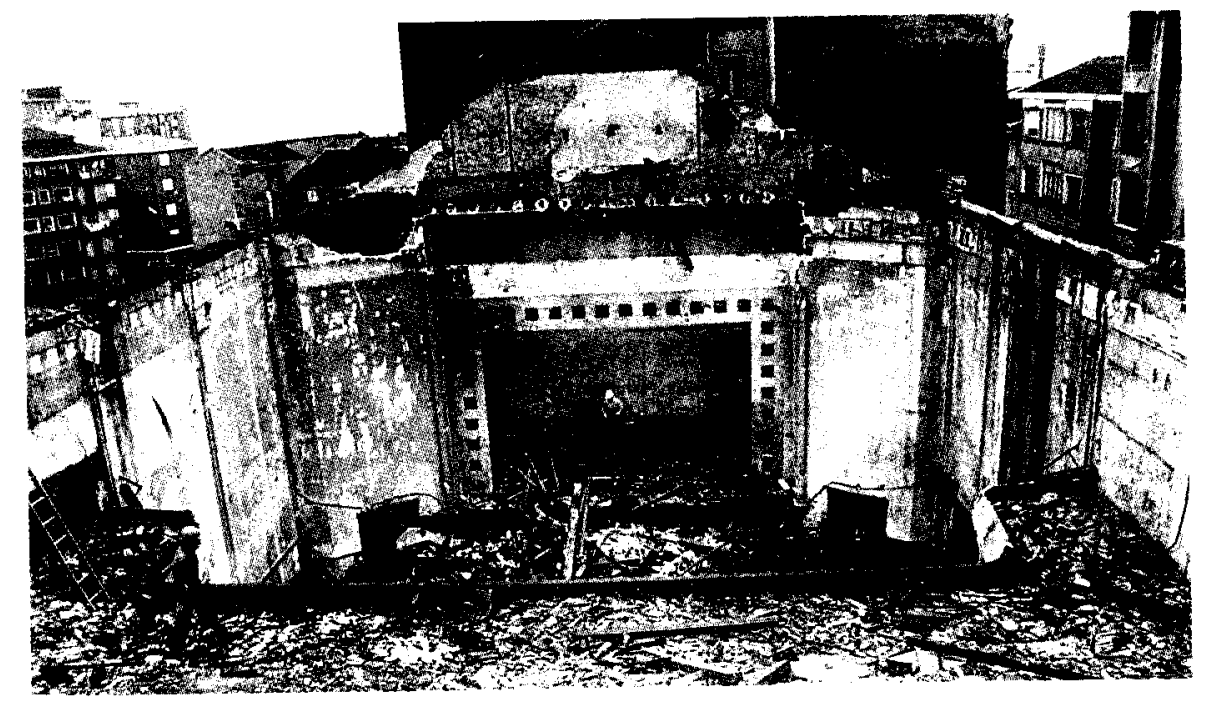

Fig. 16. Escenario visto desde el anfiteatro. 
El estado lamentable en el que se encontraba el edificio, abandonado desde hace dieciocho años, ha hecho olvidar su atractivo original. La limpieza de líneas quedaba subrayada por el color amarillo-crema, con el que estaba pintado el exterior.

\section{Interior}

Se accedía al patio de butacas por la calle la lberia, a través de tres vestíbulos existentes (fig. 7), que tenían paso directo por medio de las tres puertas descritas. Los dos primeros vestíbulos eran de planta rectangular, muy alargada, y estaban decorados con alicatados tipo Talavera en dos tonos de azul, verde, amarillo y blanco. Es la única decoración figurada en todo el edificio, todo el dibujo centraba a un león rampante coronado.

El tercer vestíbulo, con la misma decoración, era también rectangular, pero no tan alargado, y no daba directamente a la sala de proyección, sino a una amplia sala de espera situada debajo del escenario, tenía dos puertas que daban al patio de butacas (fig. 7).

Los servicios fueron colocados debajo del escenario, a sus extremos. El de las señoras a la izquierda y el de caballeros a la derecha. El primero produce un volumen en la fachada posterior (fig. 14) que no había sido contemplado en plano.

La planta de butacas tenía treinta filas de asientos, divididas por un pasillo longitudinal y dos transversales, formando grupos, de atrás hacia adelante, de ocho, diez y doce filas de butacas (fig. 7), con un total de trescientas setenta y seis localidades.

La orquesta, delante del escenario, era de buen tamaño y fue conservada en perfectas condiciones hasta que se cerró el cine.

El escenario estaba enmarcado arquitectónicamente por dos muros oblicuos, tanto a él como a las paredes laterales (fig. 16). En ambos muros oblicuos había una puerta doble.

El escenario era sencillo y limpio, no concuerda con el plan original del plano presentado (fig. 17), donde vemos un recargamiento decorativo. Lo que Zunzunegui realizó fue algo más acorde con toda la estructura del edificio. Pintó una línea de cuadrados en color verde oscuro, que enmarcaba la pantalla. Detrás de ésta, había un amplio escenario con escalera directa a la calle, para entrada y salida de artistas, pudiéndose utilizar el edificio cómodamente para teatro. 


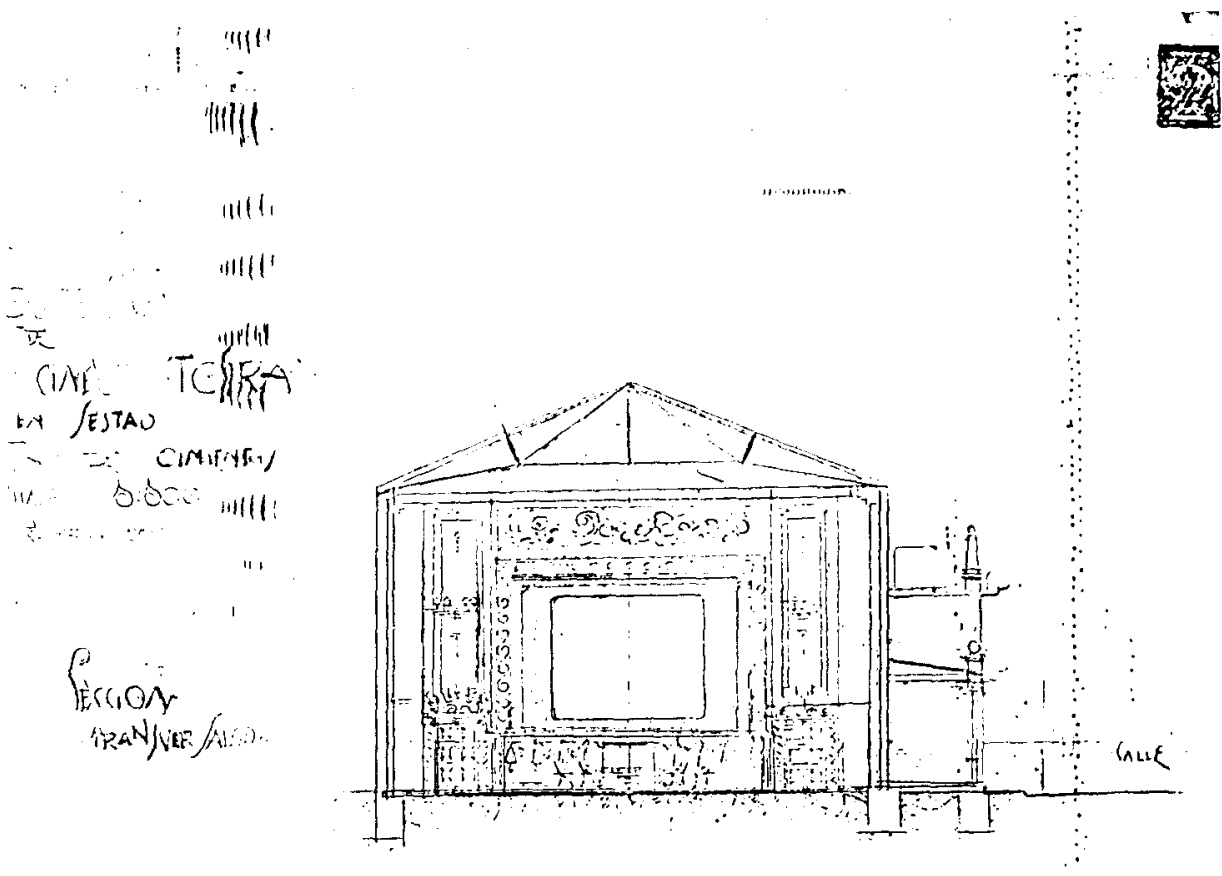

Fig. 17. Alzado de escenario de Zunzunegui.

Debajo del escenario, y aprovechando la pendiente de la calle, estaba la espaciosa sala de espera, anteriormente citada. Se encontraba flanqueada por los servicios, también mencionados, y debajo del excusado de hombres se encontraba la sala de calderas.

Había un sistema de calefacción, a base de combustión de carbón, que calentaba agua y procuraba calor a la sala, a través de radiadores. Se han conservado algunos, eran de gran tamaño y realizados en hierro fundido.

Zunzunegui, en las casas nobles, de estilo inglés, del muelle de Portugalete, ya había utilizado los nuevos sistemas de calefacción, al igual que los ascensores. La premisa de la comodidad, higiene y limpieza, la procura en todos sus edificios y, sobre todo, en los de finalidad pública: cine, teatro, escuelas y mercados.

La cabina de proyección estaba en el patio de butacas, debajo de la sala de espera del anfiteatro, a mano izquierda (fig. 18). 


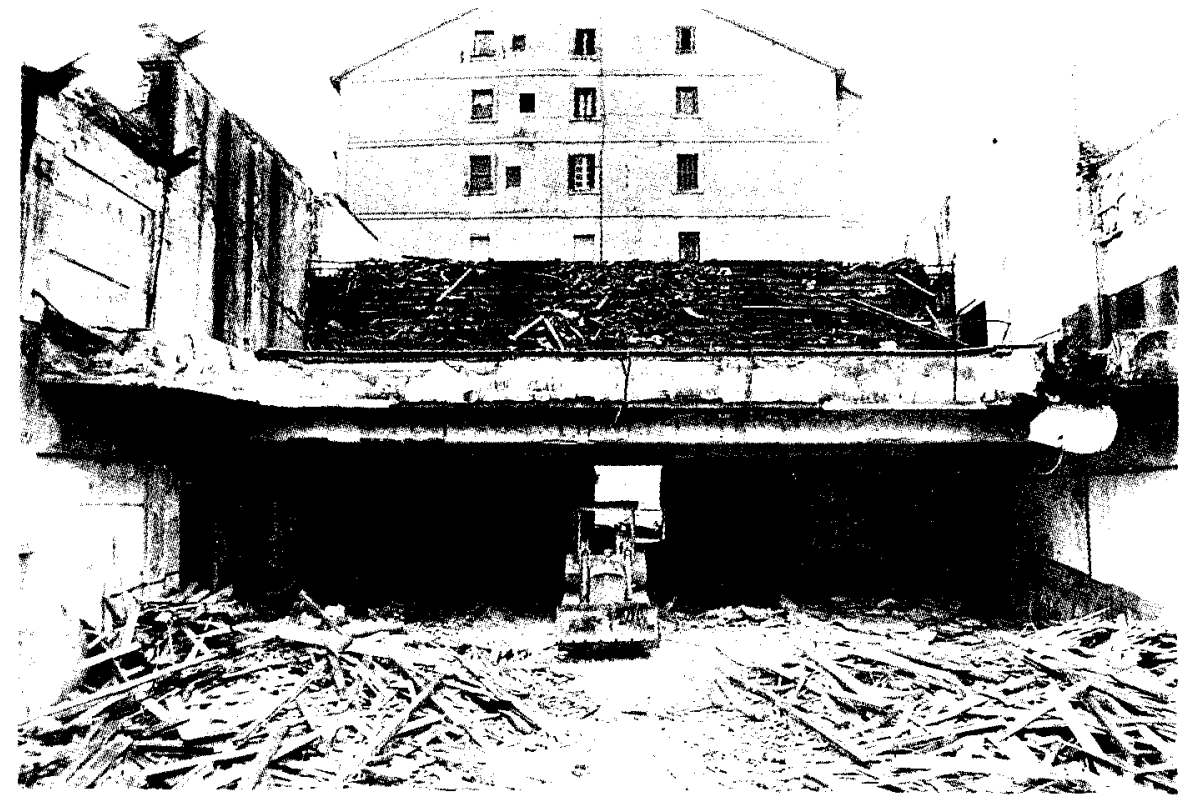

Fig. 18. Patio de butacas con cabina de proyección a la izquierda.

Para llegar al piso del anfiteatro se entraba por la fachada lateral, a través de la primera puerta de la izquierda, que comunicaba inmediatamente con escaleras de piedra, accediendo a una sala de espera. Ésta era semejante y axialmente opuesta a la del patio de butacas. En aquella se aprovechó el desnivel del terreno para colocarla debajo del escenario, ahora se aprovecha la elevación del anfiteatro para conseguir este entrepiso. En él encontramos los aseos a los extremos, el de señoras a la derecha y ocupando el saliente de la fachada (fig. 14) y el de caballeros a la izquierda, aquí hay que observar que el arquitecto proyectó otro volumen saliente paralelo al anterior, pero no se realizó en esa fachada sino en la trasera, como ocurre en los baños de señoras de la planta de butacas.

De esta zona de entrepiso se llegaba al anfiteatro (fig. 9), siguiendo las escaleras que subían de la planta baja y desembocaban lateralmente en el anfiteatro.

Este piso contaba con veinte filas de asientos corridos, dos filas de peldaños hacían más fácil el acomodo. Todo ello era de madera, a di- 
ferencia de las cuarenta y tres butacas en torno a la balconada, preferencia, que estaban forradas. En total, se le calcula un aforo de casi quinientas personas que, sumadas con las butacas de patio, nos dan alrededor de las novecientas localidades.

El interior únicamente poseía decoración en relieve en la parte superior de las paredes, a modo de cornisa, y en las pilastras una especie de triglifos. Toda la decoración es geométrica, aunque es tan escasa que en realidad pasaba desapercibida, únicamente destacaba el fuerte contraste de colores.

El color sí juega un papel importante. El interior estaba pintado de un azul grisáceo; de amarillo muy fuerte en torno a la pantalla; verde oscuro los cuadros alrededor del escenario y la mitad inferior de todas las paredes internas, este color también lo utilizó para las puertas y ventanas. Las vigas que aguantaban el anfiteatro eran de color rojizo. Este contraste de color recuerda a la Escuela de Viena que perseguia la sobriedad, el racionalismo, la armonía de proporciones y el rigor ornamental, manteniendo limpios los parámetros que dejan al descubierto el material o coloreándolo violentamente.

Zunzunegui no fue un teórico, ni dejó sus ideas escritas, no se conoce ningún escrito donde abogue por una tendencia artística determinada. Pero en su quehacer, vislumbramos que estaba al día y que conocía las tendencias modernas, tanto en materiales como en formas, funciones y estilos.

En la obra de Zunzunegui, en su aspecto formal, se observan tres modos de trabajar. Así nos han llegado lujosos edificios, caracterizados por un eclecticismo con líneas de gusto inglés. En línea paralela, se puede comprobar que no tuvo ningún perjuicio en utilizar los gustos nacionalistas, probablemente siguiendo las pautas que dio Vicente Lampérez y que Leonardo Rucabado llevó a su máxima expresión en los palacetes de Neguri.

Santos Zunzunegui aplicó ambos estilos, destinados a la nueva burguesía vasca, en el muelle de Portugalete (fig. 19).

Por otro lado le interesó el edificio con reminiscencias vascas. Realizó en estilo neovasco abundantes casas de vecindad, ya fueran para una o varias familias, como el n. ${ }^{\circ} 10$ de la calle San Diego en Sestao. Incluso en las agrupaciones de casas sociales, las ya mencionadas casas baratas de Sestao tienen una decoración neovasca.

En tercer lugar nos encontramos con unos edificios totalmente exentos de decoración, realizados en un lenguaje limpio y claro, en la más pura línea funcionalista y con planteamientos racionalistas. Son los que realiza 


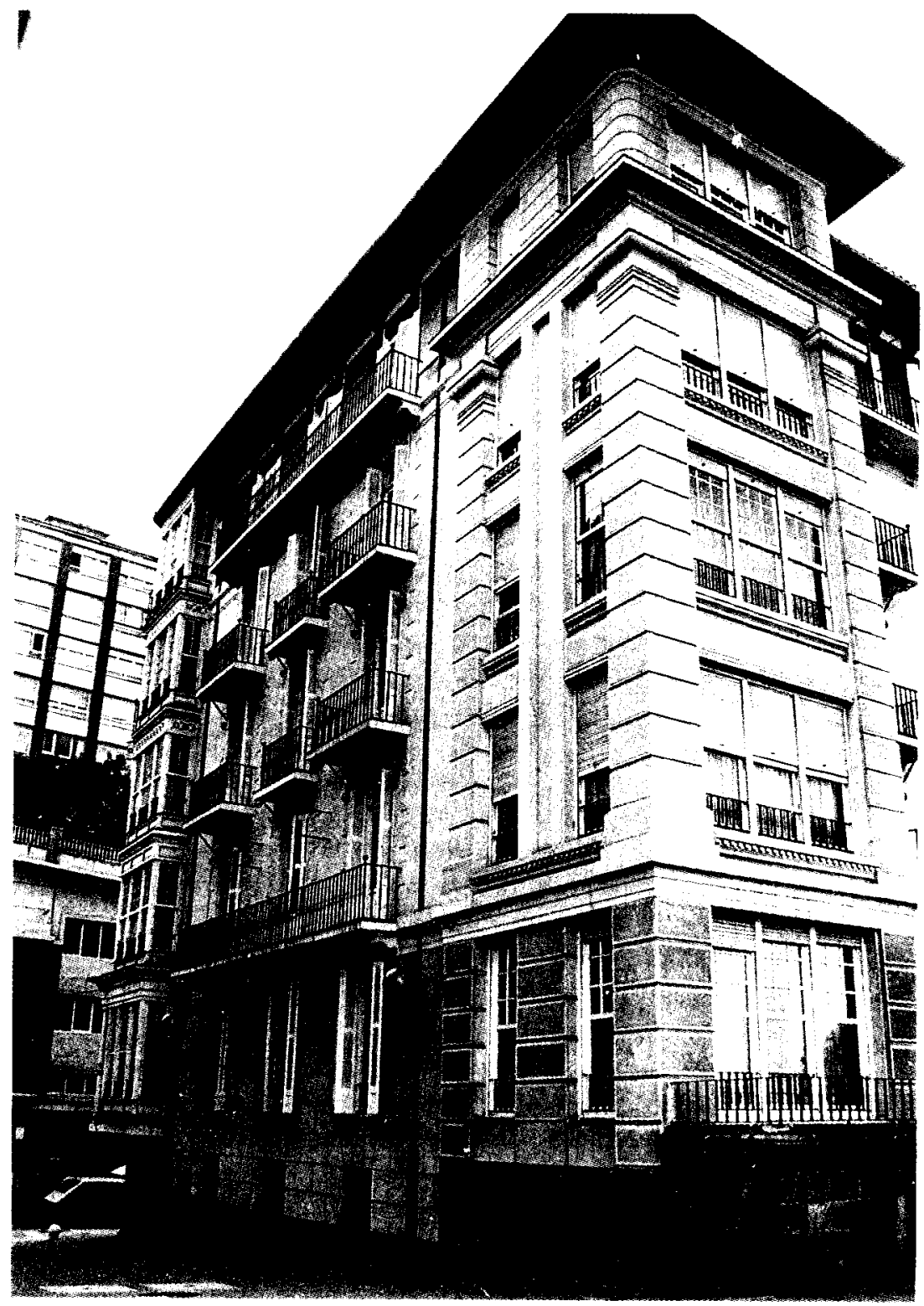

Fig. 19. Casa noble del muelle de Portugalete. 
en torno al año 30, cuando las nuevas corrientes europeas se van introduciendo en España y los nuevos materiales, hierro, vidrio y hormigón, se empiezan a utilizar sin miedo. En este grupo podemos incluir el Cine de Sestao, el Mercado de Abastos de Portugalete (fig. 15), mucho más racionalista que el cine, donde prima el vidrio y el hormigón, en una limpieza de línea total. El edificio del Partido Nacionalista Vasco de Portugalete, o el proyecto de agrupación de viviendas, conocido con el nombre de Grupo Sindical Social, sito paralelo a la calle las Llanas de Sestao, que no vio realizar por morir cuando todavía no se habían comenzado las obras.

Probablemente el aspecto racionalista sea el más interesante de la obra de Zunzunegui, donde demostró conectar con las necesidades del municipio, y desarrolló los planteamientos teóricos dados en el extranjero, adaptándolos a unas necesidades y características concretas, de la zona donde ejercía de arquitecto municipal, e intentando respetar el sentir de una gran masa de obreros, que eran quienes masivamene acudian a sus construcciones, ya fuera al mercado, al cine o habitaban las viviendas proteccionistas. 
